Supporting Information for:

\title{
Rapid Synthesis of Elastomers and Thermosets with Tunable Thermomechanical Properties
}

Leon M. Dean, ${ }^{\dagger, \dagger, \S}$ Qiong Wu, $,+,, \S, \|$ Omar Alshangiti, ${ }^{\dagger, \S, \|}$ Jeffrey S. Moore, ${ }^{*},, \S,, \|$ and Nancy R. Sottos ${ }^{*}, \dagger, \S$

*Denotes equal contribution

* Denotes corresponding author

${ }^{\dagger}$ Beckman Institute for Advanced Science and Technology,

$\S$ Department of Materials Science and Engineering,

" Department of Chemistry, University of Illinois at Urbana-Champaign, Urbana, Illinois 61801, United States 


\section{Materials and Experimental Methods:}

Chemicals. 1,5-Cyclooctadiene (COD) and tributyl phosphite (TBP) were obtained from Tokyo Chemical Industry (TCI). endo-Dicyclopentadiene (DCPD), second-generation Grubbs' catalyst (GC2), and phenylcyclohexane were obtained from Sigma-Aldrich. To prepare the monomer for FROMP, DCPD (solid at room temperature) was melted in an oven at $60{ }^{\circ} \mathrm{C}$ and then mixed with desired amount of COD, by volume, to obtain the co-monomer mixtures with 5-100 vol\% of COD. The composition of all co-monomer mixtures (and corresponding copolymers) are volume $\%$, unless otherwise mentioned. The addition of at least $5 \%$ of COD lowers the melting point of DCPD below room temperature, obtaining liquid co-monomer mixtures suitable for FROMP studies. Prior to FROMP, COD and all co-monomer mixtures were purified by passing them through basic alumina plugs to remove inhibitors (such as butylated hydroxytoluene, BHT). All other chemicals were used as received without further purification.

Liquid resin preparation. The necessary amount of pure COD or co-monomer mixture was measured out in a scintillation vial. In a separate vial, GC2 $(0.625 \mathrm{mg}$ per $\mathrm{mL}$ of monomer for all studies) was dissolved in phenylcyclohexane (50 $\mu \mathrm{L}$ per mg GC2) and the mixture was sonicated for 10 minutes. Unless otherwise mentioned, 1 equiv of TBP $(0.319 \mu \mathrm{L}$ per mg GC2) was added to the GC2 solution and then combined with the monomer.

Front velocity and temperature measurements. To a $13 \times 100 \mathrm{~mm}$ test tube, $8 \mathrm{~mL}$ of the freshly prepared monomer mixture was immediately transferred. FROMP was initiated from the top of the test tube using a soldering-iron tip. A video of the propagation of the front was recorded and frontal velocity was calculated using the slope of the best fit line of position versus time (Video S1). To measure the maximum front temperature, a T-type thermocouple (TMQSS, Omega) was inserted and fixed at the center of the test tube before initiating FROMP.

GPC and NMR measurements. Small pieces of crystallized FPCOD were collected from three samples of different batches for analysis. Each sample was dissolved by stirring overnight, 
at $10 \mathrm{mg} \mathrm{mL}^{-1}$ concentration, in either HPLC grade THF (for GPC) or $\mathrm{CDCl}_{3}$ (for NMR), both containing ca. $5 \mathrm{vol} \%$ of ethyl vinyl ether to quench the metathesis reaction. GPC was measured by a Waters Breeze 2 systems with Styragel HR columns and tetrahydrofuran (THF, HPLC grade, contains $100 \mathrm{ppm} \mathrm{BHT)}$ as eluent $\left(1 \mathrm{mg} \mathrm{mL}^{-1}\right.$ flow rate). The molecular weight and dispersity were determined by a calibration curve from polystyrene standards (from PSSPolymer Standards Service). ${ }^{1} \mathrm{H}$ NMR was measured by Bruker Ascend $500 \mathrm{MHz}$ instrument.

Differential scanning calorimetry (DSC). The heat of reaction $\left(H_{r}\right)$ for ROMP of $100 \%$ COD was determined via DSC measurements on freshly prepared monomer mixtures (2-3 mg each). The measurements were performed using a TA Instruments Discovery DSC250 from 50 to $200{ }^{\circ} \mathrm{C}$ at ramp rates of $5,7,10$, and $15{ }^{\circ} \mathrm{C} \min ^{-1}$. The heat of reaction was calculated by integrating heat flow versus time between 10 and $150{ }^{\circ} \mathrm{C}$ after baseline correction. Glass transition temperature $\left(T_{g}\right)$ was determined via DSC measurements on frontally polymerized samples (5-10 mg each). For 5\%-75\% COD samples, the measurements were performed using a TA Instruments Discovery DSC250 with a refrigerated cooling system, which has a lower temperature limit of $-90{ }^{\circ} \mathrm{C}$. For $100 \%$ COD samples, the measurements were performed using a TA Instruments Q20 DSC with a liquid nitrogen cooling system, which can access temperatures below $-130{ }^{\circ} \mathrm{C}$. Heat-cool-heat cycles were performed at $10{ }^{\circ} \mathrm{C} \mathrm{min}^{-1}$ in the appropriate temperature range, and the $T_{g}$ was taken as the inflection point of the first heat cycle. Copolymer DSC $T_{g}$ results were fit to the Fox equation:

$$
T_{g, \text { copolymer }}=\left(\frac{w_{C O D}}{T_{g, p C O D}}+\frac{w_{D C P D}}{T_{g, p D C P D}}\right)^{-1}
$$

where $w_{i}$ is the monomer weight fraction. The degree of cure $(\alpha)$ for FPCOD samples was calculated by the following equation:

$$
\alpha=1-\frac{H_{\text {residual }}}{H_{r}}
$$


where $H_{r}$ is the heat of reaction determined above, and $H_{\text {residual }}$ is determined by integrating residual heat flow versus time for the first heat cycle between 50 and $150{ }^{\circ} \mathrm{C}$ after baseline correction.

Dynamic mechanical analysis (DMA). Copolymer samples were frontally polymerized in molds pre-heated to $60{ }^{\circ} \mathrm{C}$, and then cut into strips with approximate dimensions of $0.8 \times 4 \times$ $30 \mathrm{~mm}$ using razor or scissor blades. Temperature ramps were performed in tension using a TA Instruments RSA-G2 DMA with a refrigerated cooling system. All tests were performed using $5{ }^{\circ} \mathrm{C} \min ^{-1}$ ramp rate, $10 \mathrm{~mm}$ fixture gap, $1 \mathrm{~Hz}$ frequency, and $0.1 \%$ strain. $T_{g}$ was defined as the maximum of $\tan (\delta)$, and the approximate molecular weight between cross-links $\left(M_{c}\right)$ was calculated from the storage modulus $\left(E^{\prime}\right)$ in the rubbery regime using the following equation:

$$
M_{c}=\frac{3 \rho R T}{E_{T_{g}+70 \mathrm{~K}}^{\prime}}
$$

where $\rho$ is density and $R$ is the universal gas constant.

Tensile testing. ASTM standard D638 type IV dogbone samples were frontally polymerized in molds pre-heated to $50^{\circ} \mathrm{C}$. Tensile tests were performed at room temperature on the dogbone samples using an Instron 5984 universal testing system equipped with a $5 \mathrm{kN}$ load cell and a video extensometer. Samples were subjected to an extension rate of $50 \mathrm{~mm} \mathrm{~min}^{-1}$ until failure. Tensile modulus was calculated in the linear region between $0-1 \%$ strain. Outside the range of the video extensometer, the elongation was calculated from the crosshead displacement.

$X$-ray scattering. FPCOD samples were characterized by transmission wide-angle X-ray scattering (WAXS) using a Xenocs GeniX3D Cu Ka X-ray source (1.54 $\AA$ ) and a Pilatus 2D detector. A rod beam stop placed in front of the detector was used to attenuate the primary beam. The sample-to-detector distance was calibrated with silver behenate powder. The scattering patterns were collected with a 30-minute exposure at ambient conditions. The $2 \mathrm{D}$ diffraction data were radially averaged using FIT2D software and the intensity was plotted as a function of scattering vector $q$. 
Swelling tests. A solution of 5:1 (by weight) of toluene/ethyl vinyl ether was prepared. A sample mass of $0.1-0.2 \mathrm{~g}$ of frontally polymerized copolymer was cut using scissor blades and placed into the solvent solution, and the change in mass was measured over time. After 48 hours, copolymer samples with 5\% and 25\% COD reached maximum swelling, while those with 50\% and $75 \%$ COD started to fall apart into multiple small pieces of swollen gel that prevented further measurement, indicating a low degree of crosslinking.

Gradient material fabrication. Three $1 \mathrm{~mL}$ portions of liquid resin containing $10 \%, 15 \%$ and $25 \%$ COD, respectively, were sequentially added by a syringe into a rectangular glass mold with a thickness of $2 \mathrm{~mm}$. Since COD has a lower density than DCPD, the density of upper layer is less than that of lower layer. Therefore, careful injection prevents mixing and achieves three-layer liquid preparation. FROMP was initiated from the top by a soldering iron (Video S4). After FROMP finished and the sample cooled down, the sample was removed from the mold and cut into desired shapes.

Shape memory tests. The original (permanent) shape of the sample was determined by the shape of the mold during FROMP processing and subsequent cutting operations. The programmed (temporary) shape was prepared by heating the sample to $120{ }^{\circ} \mathrm{C}$ (above the highest $T_{g}$ ), deforming the sample to the desired shape, and maintaining this shape while cooling to room temperature. To recover the original shape, the sample was uniformly heated in an oven to $120^{\circ} \mathrm{C}$ (Videos S5-S8). 
Additional Tables and Figures:

Table S1. Properties of polymers prepared by FROMP.

\begin{tabular}{cccccccc}
\hline Sample Type & $\begin{array}{c}\text { COD: } \\
\text { DCPD } \\
\text { volume } \\
\text { ratio }\end{array}$ & $\begin{array}{c}\text { COD: } \\
\text { DCPD } \\
\text { molar } \\
\text { ratio }\end{array}$ & $\begin{array}{c}\mathrm{T}_{\mathrm{g}} \\
{\left[{ }^{\circ} \mathrm{C}^{\mathrm{a})}\right.}\end{array}$ & $\begin{array}{c}\mathrm{T}_{\mathrm{g}} \\
{\left[{ }^{\circ} \mathrm{C}\right]^{\mathrm{b})}}\end{array}$ & $\begin{array}{c}\text { Tensile } \\
\text { modulus } \\
\left.[\mathrm{MPa}]^{\mathrm{c}}\right)\end{array}$ & $\begin{array}{c}\text { Tensile } \\
\text { strength } \\
{[\mathrm{MPa}]^{\mathrm{c})}}\end{array}$ & $\begin{array}{c}\text { Elongation } \\
\text { at failure } \\
{[\%]^{\mathrm{c})}}\end{array}$ \\
\hline $\begin{array}{c}\text { FPCOD } \\
\text { (this study) }\end{array}$ & $100: 0$ & $100: 0$ & $-89.7 \pm 0.4$ & - & $3.1 \pm 0.8$ & $1.48 \pm 0.39$ & $\begin{array}{c}1280 \pm \\
210\end{array}$ \\
& $75: 25$ & $77: 23$ & $-67.0 \pm 1.0$ & $-63.0 \pm 0.9$ & $3.2 \pm 0.2$ & $1.30 \pm 0.01$ & $123 \pm 6$ \\
& $50: 50$ & $52: 48$ & $-27.8 \pm 1.7$ & $-23.2 \pm 0.5$ & $5.6 \pm 0.6$ & $1.77 \pm 0.03$ & $176 \pm 2$ \\
COD-DCPD & $40: 60$ & $42: 58$ & - & $-6.2 \pm 0.9$ & $6.1 \pm 0.3$ & $2.61 \pm 0.30$ & $300 \pm 18$ \\
copolymers & $33: 67$ & $35: 65$ & - & $16.5 \pm 0.3$ & $48 \pm 13$ & $13.4 \pm 3.0$ & $446 \pm 69$ \\
(this study) & $25: 75$ & $27: 73$ & $32.1 \pm 1.6$ & $43.1 \pm 0.5$ & $1390 \pm 150$ & $31.8 \pm 2.8$ & $284 \pm 78$ \\
& $5: 95$ & $5: 95$ & $113.8 \pm 0.5$ & $126.8 \pm 0.3$ & $1870 \pm 70$ & $52.1 \pm 0.7$ & $72 \pm 40$ \\
pDCPD $^{[1,2]}$ & $0: 95^{\mathrm{d})}$ & $0: 95^{\mathrm{d})}$ & $128^{[1]}$ & - & $1950 \pm 50^{\mathrm{e})[2]}$ & $52.0 \pm 0.1^{\mathrm{e})[2]}$ & - \\
\hline
\end{tabular}

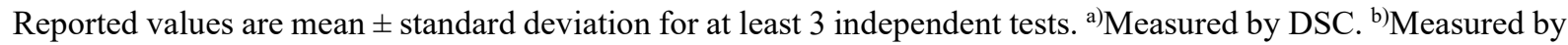
DMA using the maximum of $\tan (\delta) .{ }^{\mathrm{c}}$ Measured according to ASTM standard D638 with type IV dogbone samples and an extension rate of $50 \mathrm{~mm} \mathrm{~min}^{-1}$, unless otherwise indicated. ${ }^{\text {d) }}$ Contains $5 \mathrm{vol} \%$ of 5-ethylidene 2-norbornene as a co-monomer. ${ }^{\text {e) }}$ Measured according to ASTM standard D638 with type I dogbone samples and an extension rate of $5 \mathrm{~mm} \mathrm{~min}^{-1}$.

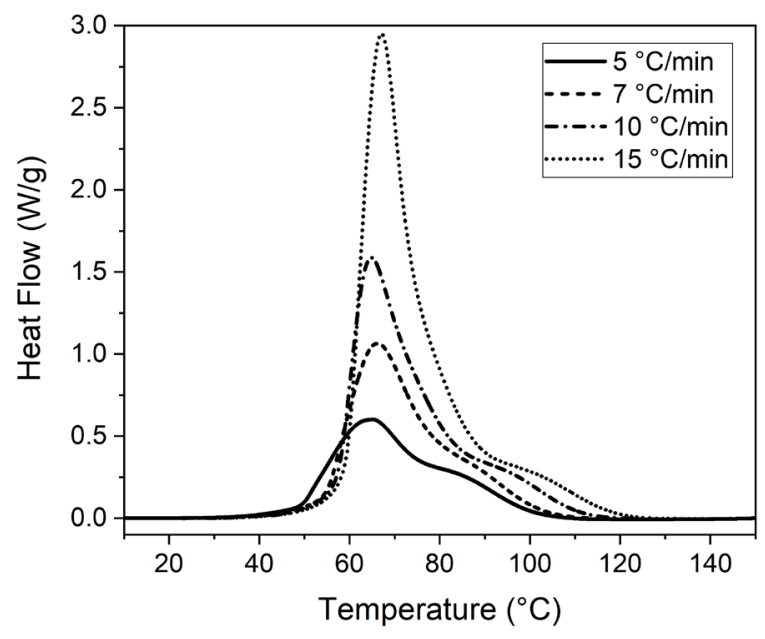

Figure S1. DSC measurements of ROMP of $100 \%$ COD at different heating rates for determination of the heat of reaction $\left(H_{r}\right)$. Direction of exothermic heat flow is up.

\footnotetext{
${ }^{1}$ Robertson, I. D.; Dean, L. M.; Rudebusch, G. E.; Sottos, N. R.; White, S. R.; Moore, J. S. Alkyl Phosphite Inhibitors for Frontal Ring-Opening Metathesis Polymerization Greatly Increase Pot Life. ACS Macro Lett. 2017, 609-612.

${ }^{2}$ Robertson, I. D.; Yourdkhani, M.; Centellas, P. J.; Aw, J. E.; Ivanoff, D. G.; Goli, E.; Lloyd, E. M.; Dean, L. M.; Sottos, N. R.; Geubelle, P. H.; et al. Rapid Energy-Efficient Manufacturing of Polymers and Composites via Frontal Polymerization. Nature 2018, 557 (7704), 223-227.
} 


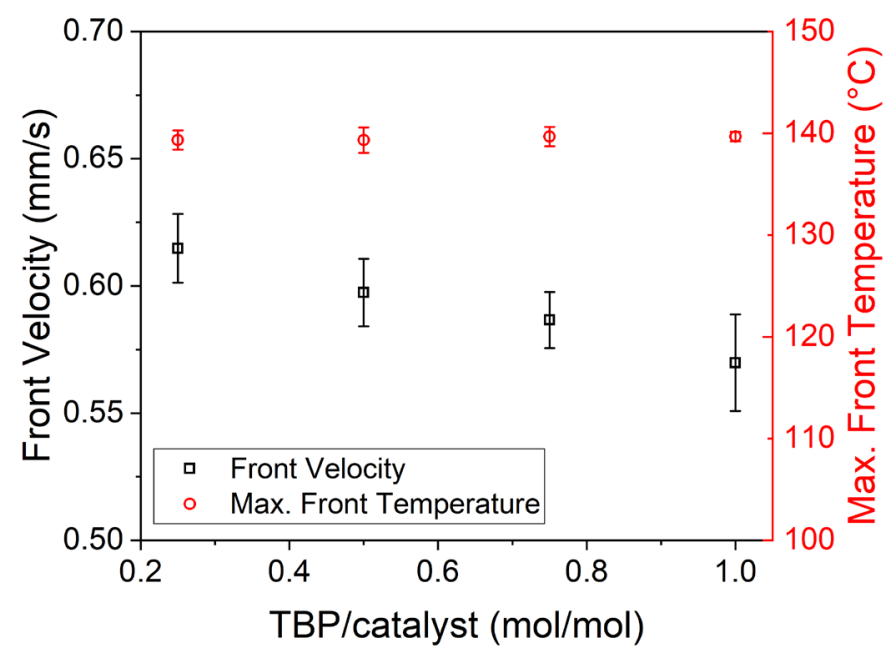

Figure S2. Front velocity and maximum front temperature of $100 \%$ COD with 90 ppm GC2 and different equiv of TBP ( 3 independent tests, error bars represent standard deviation).
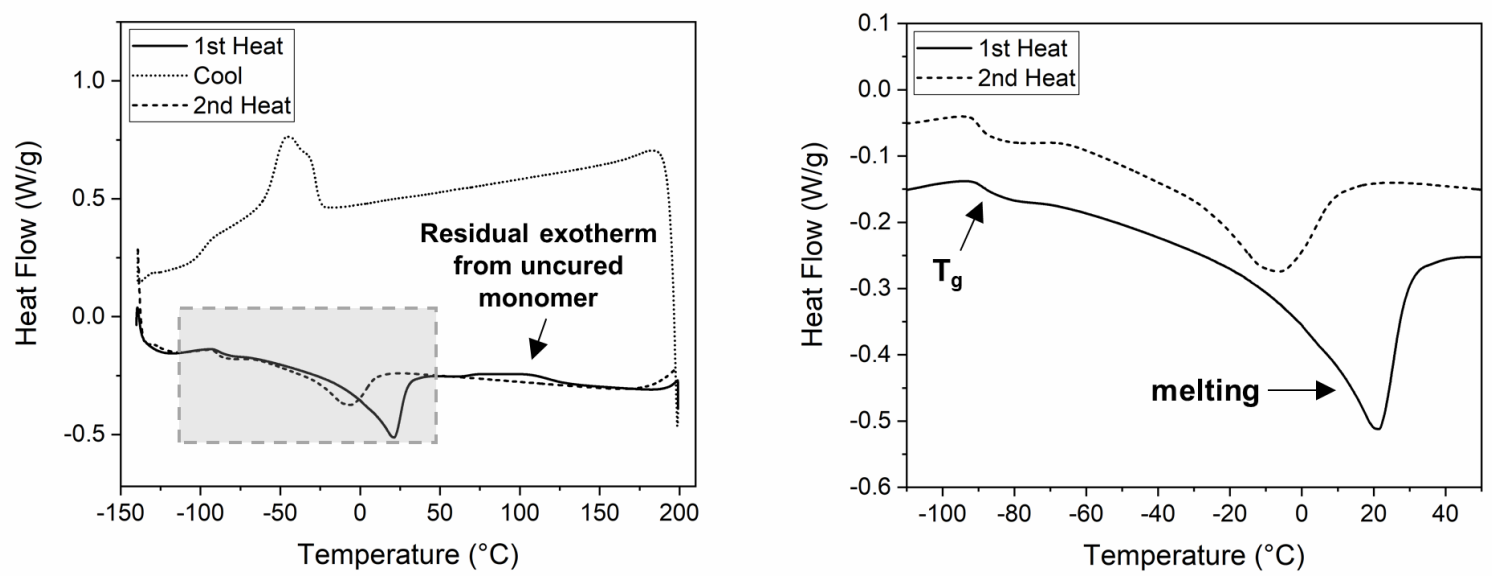

Figure S3. A representative DSC measurement of FPCOD (left). The data in the shaded box is expanded and offset vertically for clarity (right). Direction of exothermic heat flow is up. The residual exotherm from the first heating cycle is used to determine the degree of cure by Equation S2. The existence of both glass transition and melting transition indicate the semicrystalline nature of the sample. 


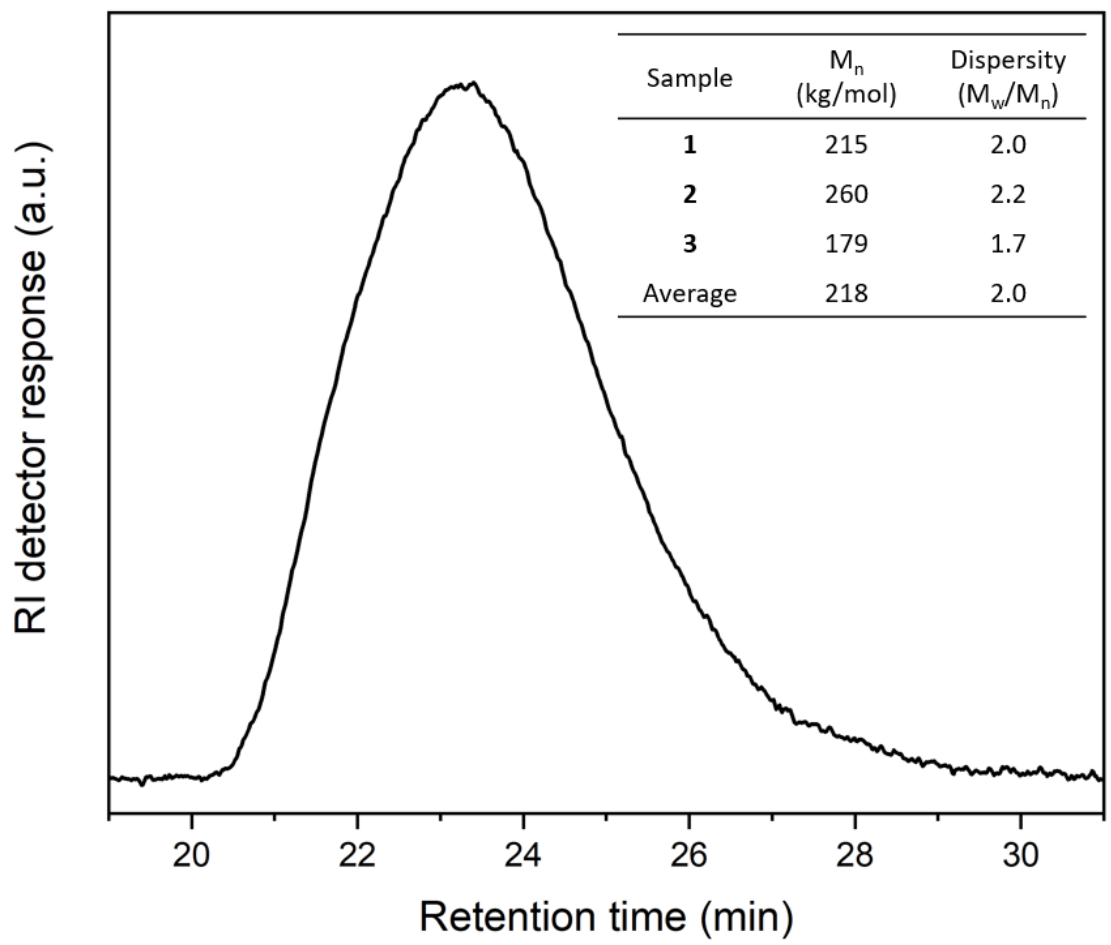

Figure S4. A representative GPC of FPCOD. The $M_{n}$ and dispersity were measured by calibration curve with polystyrene standards. Inset table shows the results from 3 individual samples.

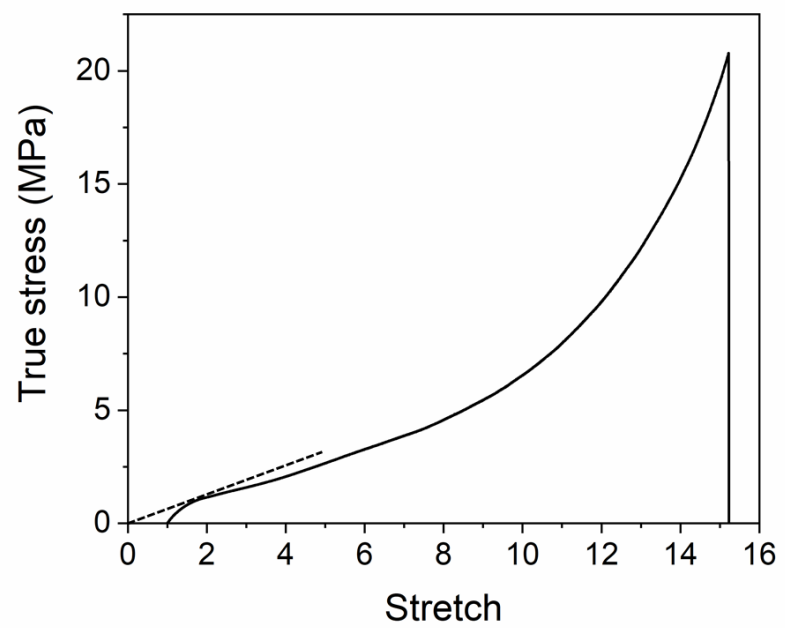

Figure S5. Representative true stress vs. stretch from tensile testing of freshly prepared FPCOD, assuming sample incompressibility. A tangent line drawn from the origin indicates yield, according to the Considère criterion. The same data is plotted as engineering stress vs. elongation in Figure 1c. 

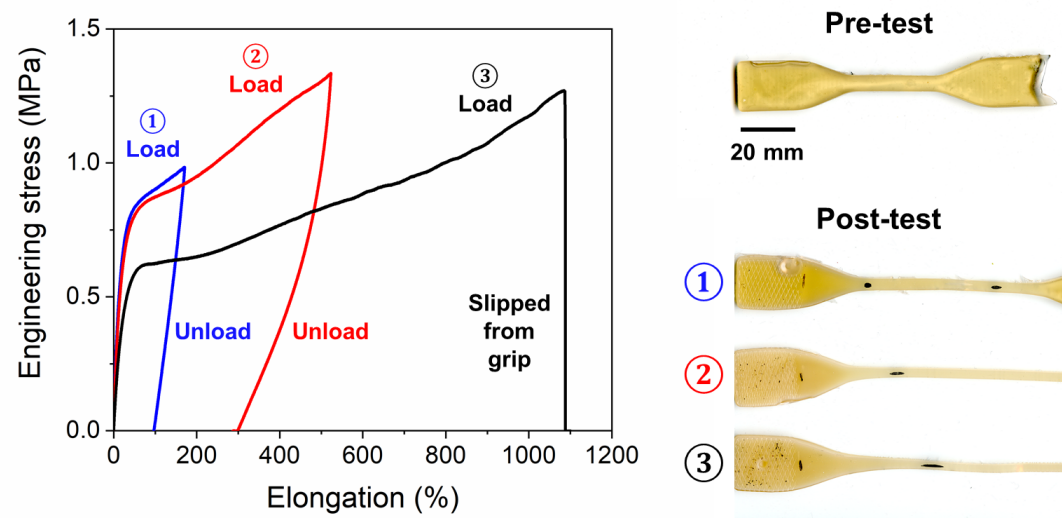

(1)

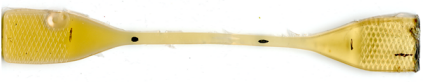

(2)

(3)

Figure S6. Tensile test data for freshly prepared FPCOD samples subjected to loading and unloading at $50 \mathrm{~mm} \mathrm{~min}$ m $^{-1}$ (left), and optical images of the samples, showing permanent deformation and whitening due to strain-induced crystallization in the gauge region (right).
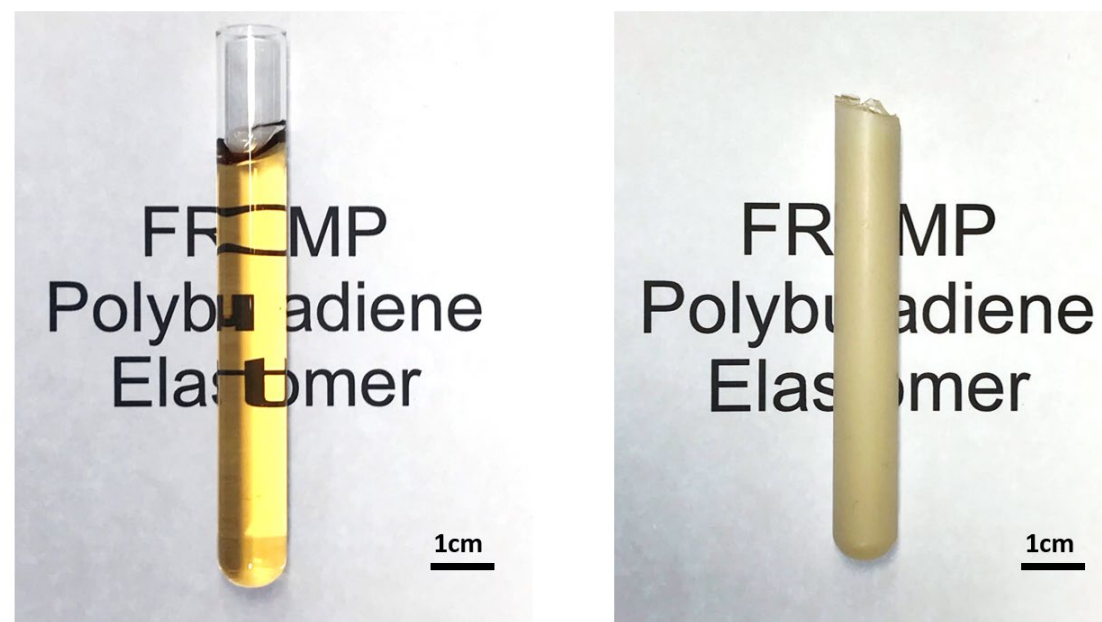

Figure S7. Optical image of freshly prepared transparent, amorphous FPCOD (left) that crystallizes into an opaque material (right) after 2 days in ambient conditions. 


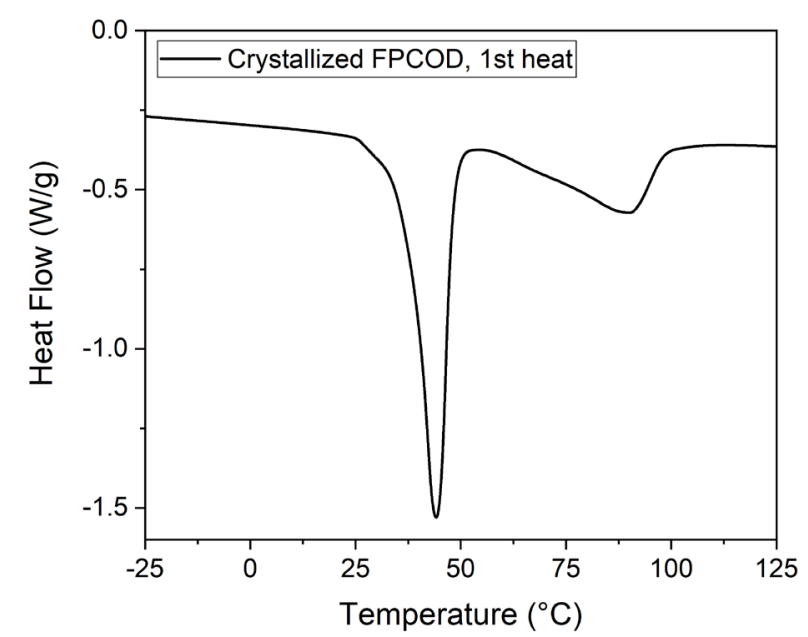

Figure S8. A representative DSC measurement of crystallized FPCOD after 2 days in ambient conditions. Direction of exothermic heat flow is up.

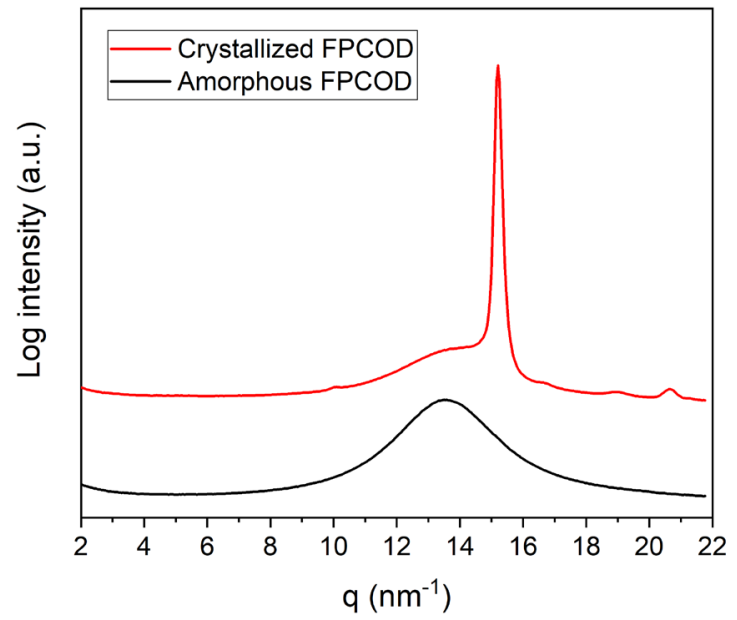

Figure S9. WAXS measurements of amorphous FPCOD and crystallized FPCOD. 

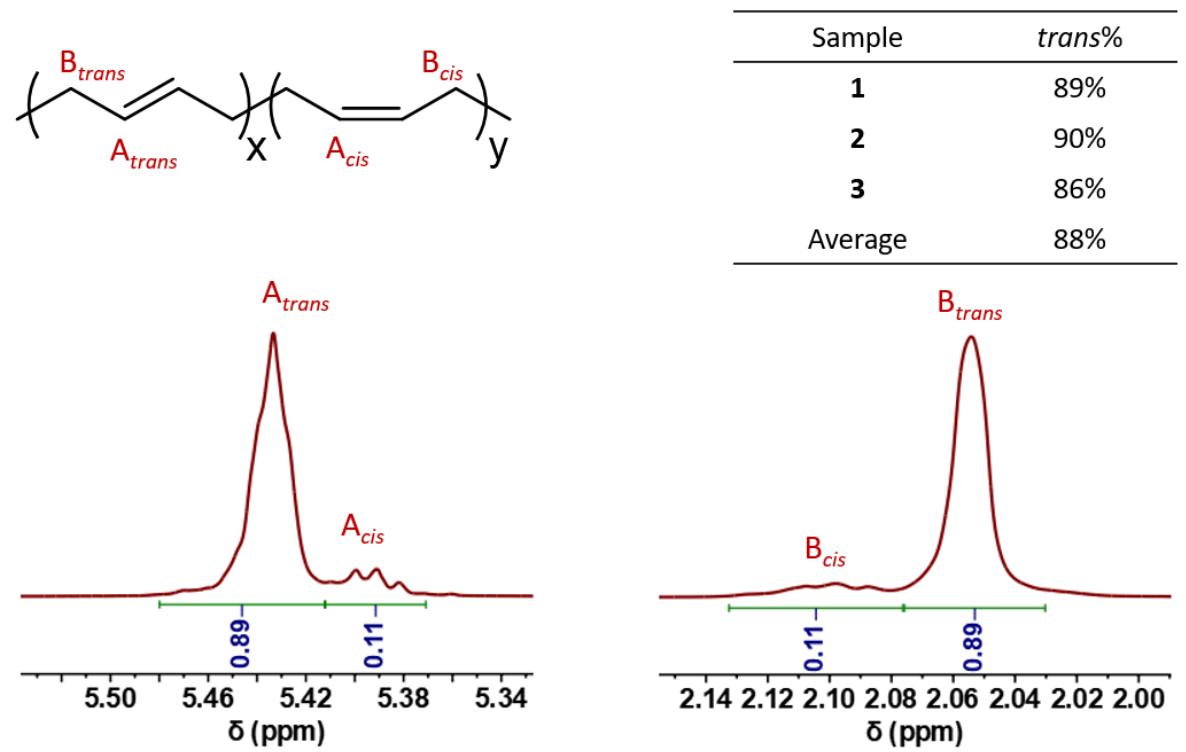

Figure S10. A representative ${ }^{1} \mathrm{H}$ NMR spectrum $(500 \mathrm{MHz})$ of FPCOD in $\mathrm{CDCl}_{3}$ (showing only the FPCOD peaks for clarity). Integration is consistent for both proton A (alkene, 5.37$5.47 \mathrm{ppm}$ ) and B (methylene, 2.03-2.13 ppm). Inset table shows the results from 3 individual samples.

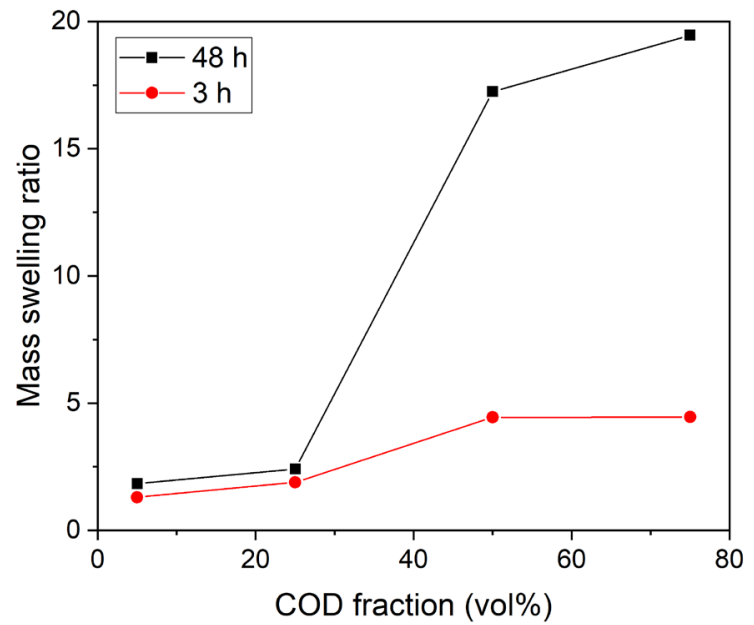

Figure S11. Swelling test results for copolymers prepared by FROMP as a function of time. Increased swelling ratio indicates a decrease in cross-link density. Samples with $50 \%$ and $75 \%$ COD start falling apart into gel pieces after 48 hours. 

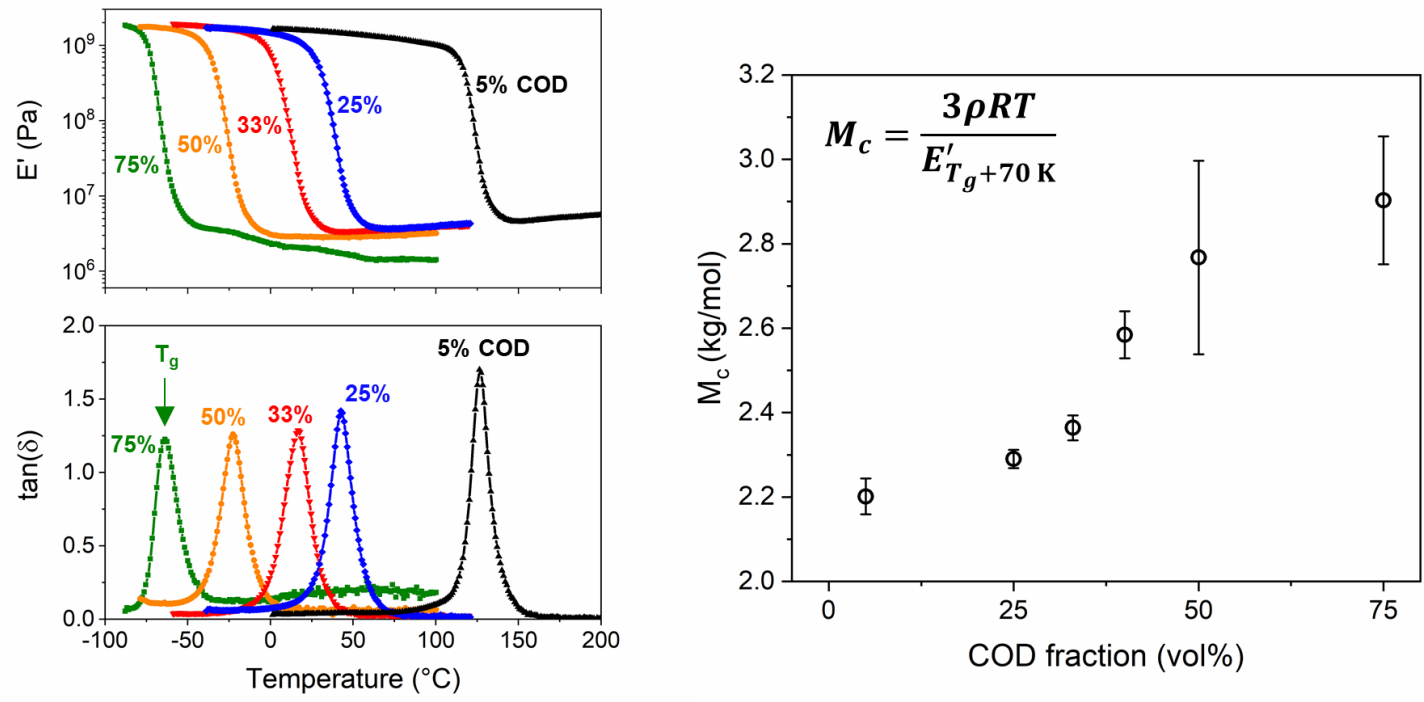

Figure S12. (left) Representative DMA temperature ramp data for copolymers prepared by FROMP. (right) The approximate molecular weight between cross-links $\left(M_{c}\right)$ is calculated from the DMA data using Equation S3.
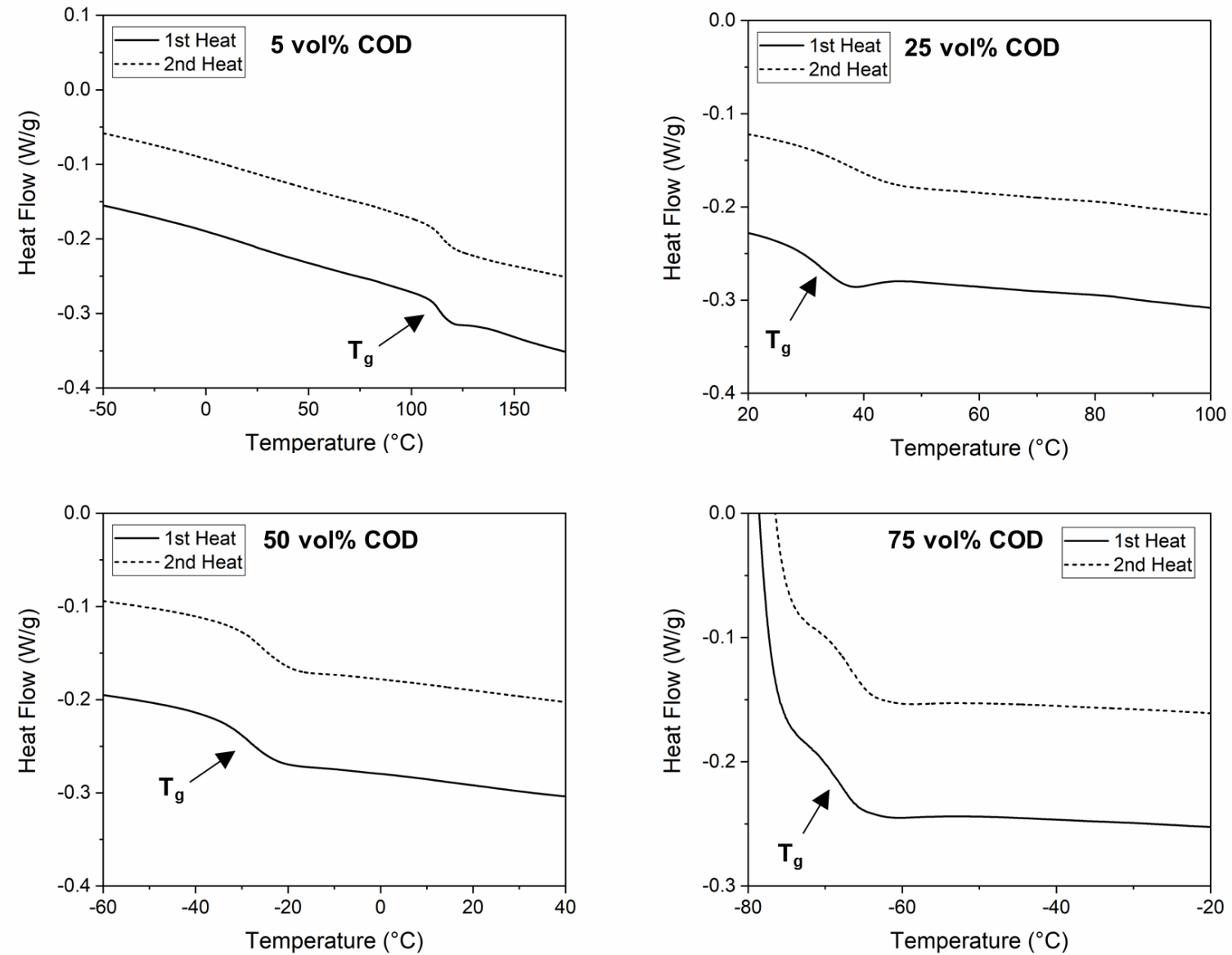

Figure S13. Representative DSC measurements of copolymers prepared by FROMP. Direction of exothermic heat flow is up. Data is offset vertically for clarity. 


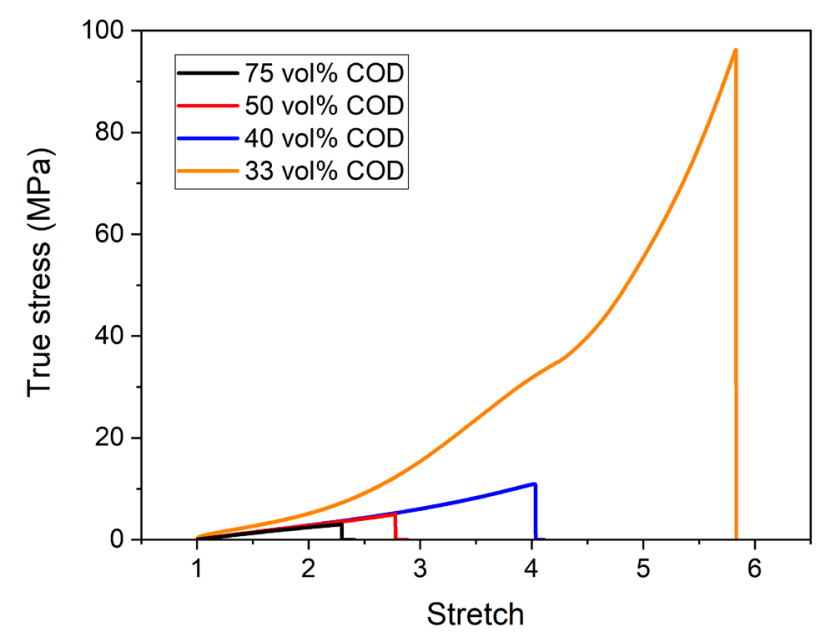

Figure S14. True stress vs. stretch for elastomeric copolymers, assuming sample incompressibility. A straight line cannot be drawn from the origin to a tangent point on any of these curves, indicating that these samples do not yield, according to the Considère criterion. The same data is plotted as engineering stress vs. elongation in Figure $3 \mathrm{~b}$.

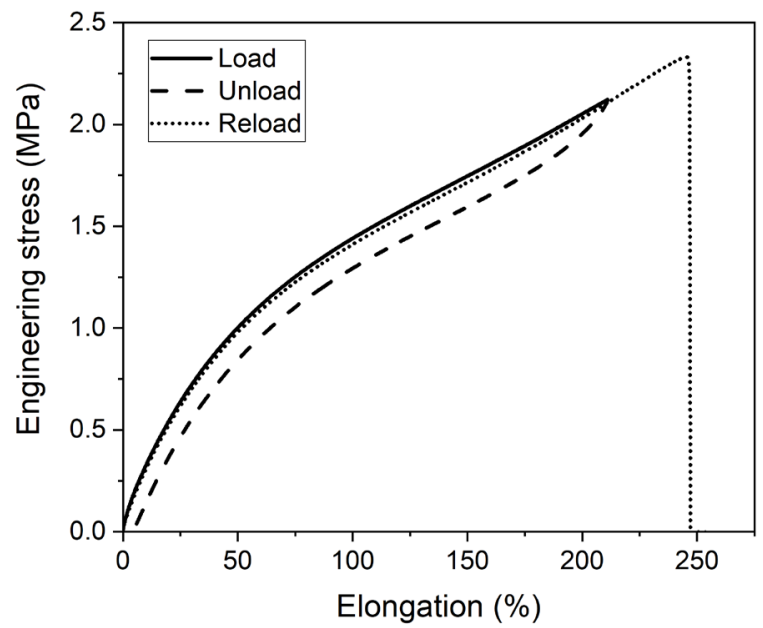

Figure S15. Tensile test data for an elastomeric copolymer with $40 \mathrm{vol} \%$ COD subjected to loading, unloading, and reloading at $50 \mathrm{~mm} \mathrm{~min}^{-1}$. 


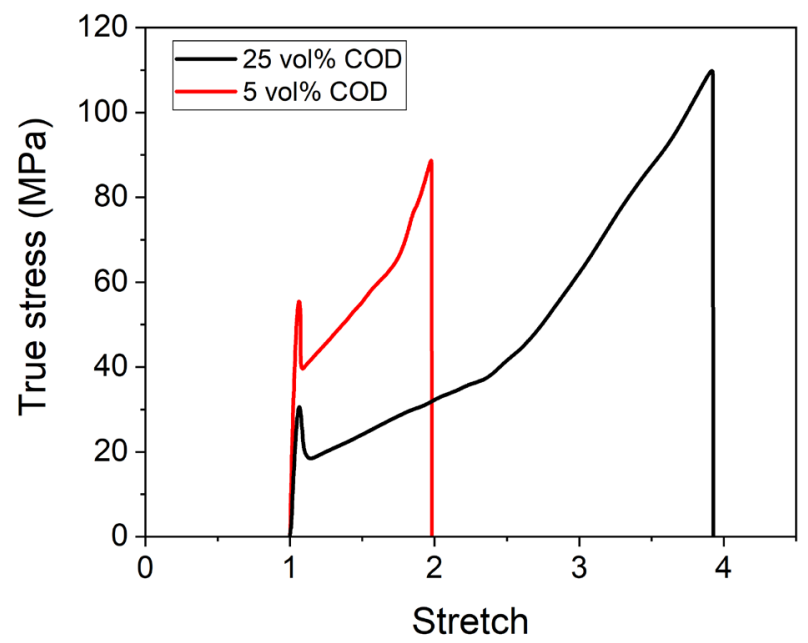

Figure S16. True stress vs. stretch for cold drawing copolymers, assuming sample incompressibility. A tangent line drawn from the origin indicates yield, according to the Considère criterion. The same data is plotted as engineering stress vs. elongation in Figure $3 \mathrm{c}$.
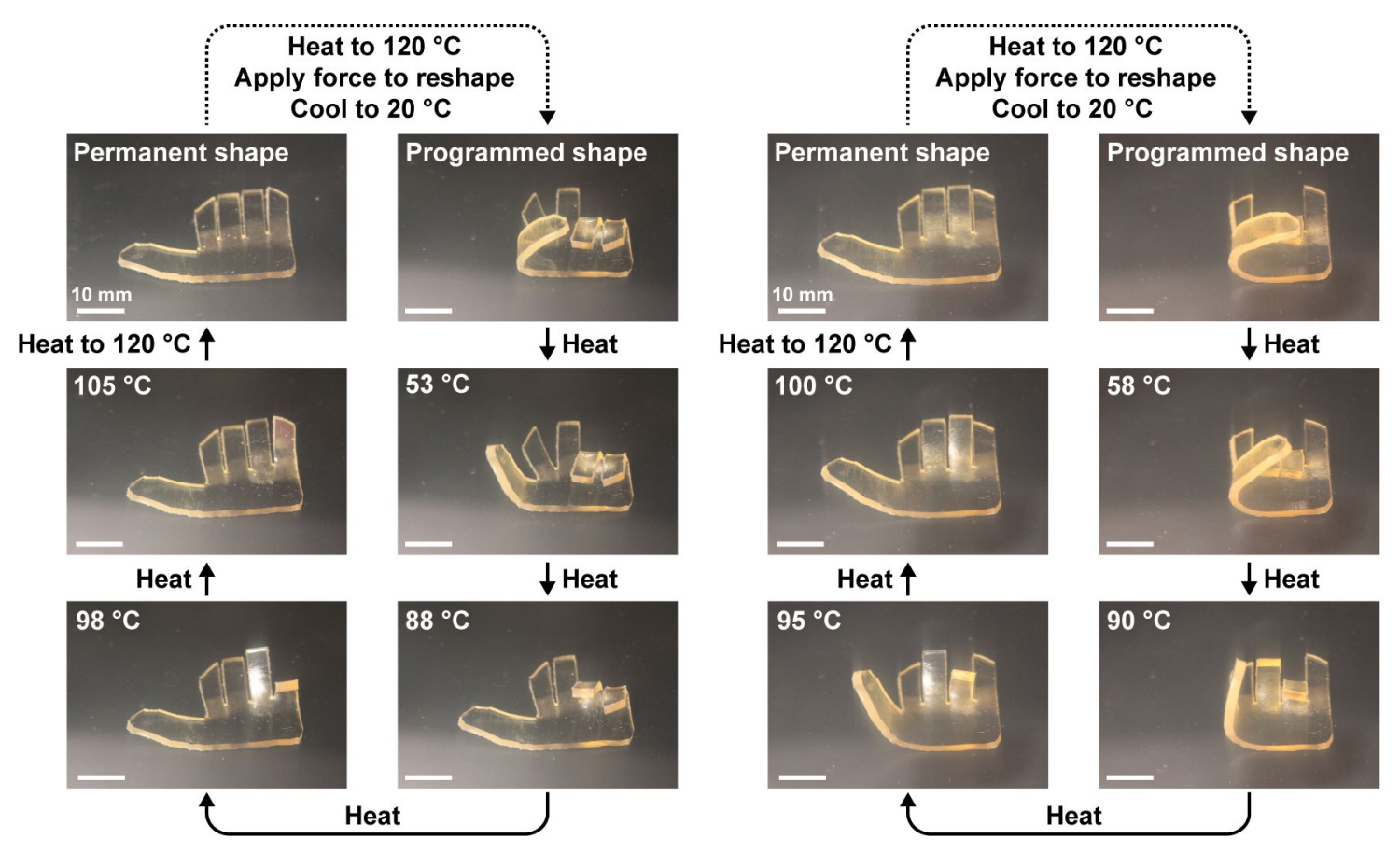

Figure S17. Multiple shape memory cycles of the same gradient material with different programmed temporary shapes (also see Videos S6 and S7). 